\title{
Leituras resistentes: fanfiction e internet vs. Cultura de massa
}

\author{
Márcio Padrão ${ }^{1}$
}

\begin{abstract}
Resumo: A tecnologia para produzir comunicação está cada vez mais nas mãos do grande público, e a internet radicalizou essa tendência na última década. É neste meio que prolifera o fenômeno da fanfiction, prática de escrever histórias baseadas em universos ficcionais personagens, cenários e acontecimentos de ficção - criados por terceiros e lançados em produtos da indústria cultural, como livros, filmes e seriados de TV. Nosso objetivo é compreender um pouco mais da dinâmica existente na publicação de fanfiction pela internet. Sobretudo, destacar as ferramentas que o meio oferece para que os escritores possam ter seus textos publicados e lidos em todo o mundo, com custo e trabalho mínimos.
\end{abstract}

Palavras-chave: Fanfiction. Indústria cultural. Cibercultura.

\begin{abstract}
The technology to produce communication is in the hands of the public, and the internet radicalized this trend in the last decade. It is in this way that the fanfiction phenomenon proliferates; it is the practical to write stories based on ficcional universes - characters, scenes and events on fiction - created by third ones and launched in products of the cultural industry, as books, films and TV series. Our objective is to understand a little more about the existing dynamics in the publication of fanfiction on Internet. Over all, to detach the tools that the media offers so that the writers can have their texts published and read in the whole world, with minimum cost and work.
\end{abstract}

Keywords: Fanfiction. Cultura industry. Ciberculture.

\section{Introdução}

No momento em que este artigo é escrito, políticos, empresas e especialistas em comunicação e tecnologia debatem as diretrizes gerais para a implantação da tecnologia digital para a transmissão televisiva no País. O assunto é vasto, indo desde a discussão sobre o padrão tecnológico escolhido para as necessidades do mercado brasileiro, passando pelas possibilidades interativas que a nova tecnologia poderá proporcionar aos consumidores, chegando até o debate sobre o conteúdo, isto é, se o público só terá acesso à produção das grandes redes ou se haverá espaço para programas de ONGs, do poder público ou até mesmo dos espectadores; o que poderia trazer um nova revolução audiovisual $^{2}$. Se o debate é pertinente, é porque é conseqüência de uma revolução ainda maior que acontece há décadas. A tecnologia para produzir comunicação, como previra Walter Benjamin, está cada vez mais nas mãos do grande público, e a internet radicalizou essa tendência na última década. Uma parcela dos consumidores de cultura de massa vê o passatempo chamado fanfiction, assunto deste artigo, como uma inovação que antecipou muitas das conquistas ainda em discussão na futura TV digital. 
Por fanfiction estamos nos referindo à prática de escrever histórias baseadas em universos ficcionais - personagens, cenários e acontecimentos de ficção - criados por terceiros. Na grande maioria dos casos, a principal inspiração do escritor de fanfiction são histórias lançadas por produtos da indústria cultural, como livros, filmes, desenhos animados, quadrinhos e seriados de TV. Por exemplo, uma fanfiction sobre Harry Potter poderá incluir na história Harry, Hermione, Rony, a Escola de Hogwarts e outros elementos da criação da escritora J. K. Rowling. O adepto desse passatempo é alguém que, por opção, transcende o status de mero consumidor dessas histórias ao recriar, ampliar, mudar o foco, subverter e/ou parodiar universos ficcionais de outros criadores em seus próprios contos. Esse novo escritor dará início, assim, a uma nova etapa na sua relação não apenas com a indústria cultural, mas com outras pessoas com particularidades e desejos em comum.

As pessoas que escrevem fanfiction, de um modo geral, possuem níveis de proximidade e identificação com o produto original bastante diferentes do público convencional. A etimologia do termo, "ficção de fã", ajuda a levantar um ponto chave sobre este objeto. De fato, estas pessoas se proclamam fãs destes produtos. Quando unidos, estes fãs se dedicam ao culto aos produtos da indústria cultural e, para isso, iniciam entre si uma infinidade de formas de manter acesa a chama do interesse sobre seus objetos de adoração. Editam fanzines com reportagens e artigos, escrevem fanfictions, desenham fanarts com os personagens preferidos; todas estas ações, a princípio motivadas pelo elemento lúdico, também acabam por formar novas leituras sobre os textos ficcionais originais. A internet acabou se tornando naturalmente o meio mais propício para que toda esta nova produção aflore, e com isso também aumentou substancialmente a articulação para novos relacionamentos entre fãs de todo o mundo.

Embora a internet também venha permitindo, atualmente, grandes experimentos no campo audiovisual - sobretudo por conta da recente popularidade do site de armazenamento de vídeos YouTube $^{3}$ - todas as previsões acerca das possibilidades interativas da TV digital ainda são (por enquanto) previsões. O que é fato, porém, é que as audiências já derrubaram o velho paradigma da comunicação de massa, no qual os papéis de emissor e receptor de uma mensagem eram pré-definidos e imutáveis. As pesquisas estatísticas de opinião, seções de cartas dos leitores e ligações telefônicas ao vivo para programas de rádio e TV - apenas para ficar em alguns exemplos mais 
conhecidos - têm servido há tempos para chegar a um entendimento entre produtores e audiência. Entretanto, a fanfiction não se configura como uma simples resposta opinativa a uma mensagem, mas é em si mesma uma mensagem inédita, criada, distribuída e até mesmo consumida de forma independente e marginal.

Os escritores de fanfiction - também chamados de ficwriters (ou fanfiqueiros, em uma adaptação para o português) - raramente não cultivam o hobby de forma isolada. Como em toda produção de cunho ficcional, é natural que haja por parte deles uma necessidade de apresentar seus textos a um público leitor. Portanto, assim que uma fanfic (ou fic, diminutivos do termo fanfiction) passa a ser divulgada por seu escritor, esta se torna uma mensagem, e seus leitores formam um novo público, gerando assim um processo comunicativo paralelo à indústria do entretenimento que "inspirou” o fenômeno.

As variadas comunidades de fãs - as fandoms - produzem fanfiction há pelo menos quarenta anos, e estas eram divulgadas e impressas de forma amadora, ou seja, em fanzines distribuídos em convenções de fãs ou por correio, na maioria das vezes. Graças às facilidades propiciadas pela internet, mídia que se popularizou a partir dos anos 1990, o gênero rapidamente deixou de ser um hábito de poucos iniciados para cair no gosto de um público cada vez mais abrangente; principalmente fora dos Estados Unidos, país onde o fenômeno mais se desenvolveu. A ligação dos fãs com os produtos de ficção da indústria cultural implicaria em uma relação que extrapola a inspiração e/ou dependência, mas joga com novos elementos dentro do contexto da mídia como entretenimento e referente da pós-modernidade. Assim, a fanfiction seria ao mesmo uma mensagem que é resposta à indústria cultural "oficial” e um canal de encontro onde os integrantes desta subcultura compartilham experiências.

Nosso objetivo é compreender um pouco mais da dinâmica existente na publicação de fanfiction pela internet. Sobretudo, destacar as ferramentas que o meio oferece para que os ficwriters possam ter seus textos publicados e lidos em todo o mundo, com custo e trabalho mínimos. Para isso, vamos descrever e analisar o funcionamento dos sites mais populares da internet para publicação de fanfiction, além de enumerar algumas das leituras mais comuns que os fãs realizam em relação aos universos ficcionais originais da indústria cultural. 


\section{Fanfiction e internet, cultura e tecnologia}

A história do site que é referência no gênero, o Fanfiction.net ${ }^{4}$, se confunde com a própria trajetória recente do gênero fanfiction na internet. Foi criado em 1998 por Xing Li, um programador de software e fã do seriado The X-Files (Arquivo X) que vivia em Los Angeles, EUA ${ }^{5}$. Devido à sua grande aceitação entre os internautas, o site comporta atualmente mais de 1,8 milhões de fanfics publicadas, subdivididas em oito gêneros distintos: anime/mangá ${ }^{6}$, livros, quadrinhos, filmes, desenhos, programas de TV, games e uma seção miscelânea, para outras mídias e formatos que não se enquadram nas demais categorias (como musicais, peças de teatro e crossovers). Muito do sucesso do Fanfiction.net se deve à simplicidade e acessibilidade de sua estrutura, combinado a um conjunto de regras bem definidas.

As categorias do site apresentam subdivisões por cânone ${ }^{7}$; por exemplo, o link para filmes traz toda a lista de fanfics organizada por ordem alfabética do filme-cânone, acrescido de um número que indica a quantidade de histórias já escritas sobre aquele cânone. Quando clicamos, as fics são apresentadas pela ordem das que foram atualizadas mais recentemente. Cada texto é encabeçado pelas informações básicas: nome ou apelido do escritor da fic, classificação etária (eles possuem uma convenção própria para classificar os textos), linguagem da fanfic, quantos reviews (comentários dos leitores) possui, gênero, datas da publicação e da última atualização. Além destas, outras características ajudam a organizar todo o material e permite uma filtragem, como a duração (capítulo único, multi-capítulo), qual o personagem principal, personagens secundários e status do trabalho (em progresso ou finalizado).

No entanto, já existem vários serviços online de publicação de fanfiction, embora todos tenham uma popularidade menor que o Fanfiction.net. Alguns exemplos: FanWorks.Org ${ }^{8}$, FicWad ${ }^{9}$, Fictionpress..Com ${ }^{10}$, SkyHawke ${ }^{11}$, AdultFanFiction.Net, ${ }^{12}$ FanDomination.Net ${ }^{13}$, MediaMiner.Org ${ }^{14}$ e FanLib ${ }^{15}$. Cada um possui visual, regras, alcance e ferramentas distintos entre si. Há ainda os sites para cânones específicos, como o TrekFanfiction.Net ${ }^{16}$ (Star Trek) e o Sugarquill.Net ${ }^{17}$ (Harry Potter). Os internautas também procuram formas alternativas de publicar e difundir fanfiction, principalmente quando não estão de acordo com as regras impostas por estes sites, pois 
alguns destes não publicam fanfics de apelo erótico ou seus editores escolhem os textos de acordo com critérios pessoais de qualidade. Assim, as mailing lists, sites pessoais, blogs e journals (como o Livejournal.com) são algumas das maneiras independentes adotadas para o ficwriter veicular e ter controle sobre seu material.

O retorno imediato do público é provavelmente uma das maiores razões para os fãs adotarem a internet como o canal definitivo para postar seus textos. A maioria dos sites de fanfiction possui um sistema de reviews para que os leitores possam apresentar comentários e opiniões sobre a história, formando assim um estreito canal de comunicação para a fandom; estritamente no campo da fanfiction, entende-se que muitos leitores do gênero também escrevem textos, e vice-versa, por isso os reviews servem como uma ferramenta para que possam trocar críticas construtivas, amadurecer a história em progresso ou fornecer idéias para outros contos. Todavia, há também a contraparte negativa: certos leitores utilizam o espaço do review para a prática do flame, que consiste em provocar intrigas e discussões agressivas online. Certos sites possuem no sistema a possibilidade de moderar a seção de comentários para minimizar os flames.

Como vimos, alguns sites dividem seu arquivo de fanfics por mídia, como livros, quadrinhos, filmes, desenhos animados, programas de TV e games. É um fato que essas mídias estão entre as mais populares e desenvolvidas na indústria cultural globalizada. Também é bastante relevante que, embora animes e mangás sejam na prática desenhos animados e quadrinhos, o fato de ambos serem encaixados em uma categoria só deles demonstra também a consolidação - e ao mesmo tempo a diferenciação - da indústria cultural japonesa na atualidade.

A proliferação da fanfiction e demais atividades da fandom também passaram por essa questão das mídias. Começou com os fanzines em papel, produzidos sob diversas formas de impressão, principalmente as mais baratas, como o mimeógrafo e a fotocópia. Com a internet, as fanfictions migraram da máquina datilográfica para o editor de textos, e daí para páginas HTML. As fanarts foram digitalizadas, seja por scanners, seja na própria produção direta dos desenhos em programas e ferramentas de design. O barateamento das câmeras de vídeo e o recente surgimento de sites de armazenamento de vídeos como o YouTube facilitaram a criação e disseminação dos fanfilms. A internet tornou-se fundamental não apenas por abrigar a produção, mas por torná-la acessível a qualquer um em qualquer parte do mundo; por ampliar os canais de 
comunicação para ampliar significativamente as fandoms; e por trazer tudo isso de forma extremamente rápida e barata, com apenas um computador doméstico e uma conexão telefônica ou por servidores de banda larga. Mesmo que um computador ainda não seja um equipamento tão barato para a maioria das pessoas, principalmente em países em desenvolvimento como o Brasil, não há como negar a exponencial popularização dessa tecnologia nos últimos anos.

O avanço da tecnologia também contagia a Indústria Cultural, pois lançou novas tendências e consolidou outras. Uma delas é a chamada franquia, que consiste em lançar a mesma criação nos mais diversos produtos licenciados. Assim, um personagem como Harry Potter, surgido no livro Harry Potter and the Philosopher's Stone (1997), já existe em diversos produtos dentro nas mais variadas mídias: além de suas seis continuações em livro, estes também estão sendo adaptados para o cinema, videogames e um projeto para um futuro parque temático de diversões. Os filmes também ganham edições em DVD para locação e venda, e este último sempre traz um disco apenas para material extra, ampliando o entretenimento relacionado ao personagem. A publicidade relacionada com a franquia também potencializa as possibilidades, pois além dos sites oficiais veicularem notícias, trailers dos filmes em versão digital, jogos online e incrementos para o computador (como proteção de tela, papel de parede e ícones para messengers), tanto o marketing oficial como o espontâneo (textos em blogs, reedições de trailers no YouTube, fóruns de discussão das novidades) se espalham rapidamente pela rede, seja por estratégias das empresas ou pela atividade da fandom. O lado negativo para a indústria do entretenimento, porém, é a igual facilidade com que o material original é pirateado ou plagiado, como os próprios filmes ou as traduções amadoras dos livros.

Queremos chegar, trazendo essa contextualização, ao fato de que estamos vivendo uma era digital onde a convergência e integração das mídias é um processo em franco andamento. A tecnologia, até o momento, tem beneficiado tanto aos produtores da indústria cultural quanto às audiências, em especial às media fandoms, que têm à disposição uma variedade cada vez maior de produtos para fruir e uma gama crescente de formas para interagir e/ou reverenciar seus cânones. Temos investigado se os fãs ficwriters desejam, nessa conjuntura, assumir o desejo de ter uma voz ativa neste processo, isto é, se a cultura digital que estamos vivendo não seja, por si só, uma 
motivação para o fã participar do cânone de alguma forma, sendo a fanfiction uma dessas maneiras.

Essa conjuntura é própria das problemáticas fornecidas pela pós-modernidade, que cada vez mais emprega a tecnologia como aliada, ou às vezes como a própria razão de ser da estética, como uma radicalização do "meio é a mensagem” de McLuhan. Também percebemos na fanfiction características defendidas pelos Estudos Culturais britânicos. A contribuição dessa corrente, sobretudo as de Raymond Williams e Stuart Hall, trouxe ares de renovação para essa aplicação do pensamento marxista na comunicação de massa e na cultura. Enquanto Richard Hoggart o primeiro pretendia "romper com o positivismo científico da objetividade sociológica e concentrar-se na 'subjetividade', no sentido de examinar a cultura em relação a vidas individuais” (HOLLANDA apud PRYSTHON: 2003, p. 135), Raymond Williams versava sobre a “identificação dos efeitos culturais das desigualdades sociais” (idem, idem) e E.P. Thompson argumenta que “a identidade da classe operária vai ter sempre um componente político e conflitual, independente de valores e interesses culturais particulares” (idem, idem).

Para a nossa pesquisa, o nome de Stuart Hall se sobressai entre os pais fundadores dos Estudos Culturais porque foi responsável por burilar e especificar diversas problemáticas desenvolvidas por Hoggart, Williams e Thompson. Hall discutiu questões históricas como a colonização e a distinção racial para chegar à outra constante em seus trabalhos: o sujeito pós-moderno formado por não uma, mas diversas identidades que o põem em freqüentes contradições. Uma de suas maiores contribuições para os estudos em Comunicação é o artigo Encoding/Decoding (Codificação/Decodificação), de 1973, no qual propõe o desenvolvimento de uma nova metodologia para o estudo das audiências. Até então, o método se baseava na noção de que, no modelo emissor-mensagem-receptor, a mensagem chegaria ao receptor com o mesmo sentido proposto pelo emissor, e os possíveis desentendimentos são considerados apenas ruídos na comunicação. Para Hall, a transmissão de mensagens não funciona dessa forma, pois os sujeitos que estão implícitos nas duas pontas do processo estão atravessados por suas próprias condições de existência, o que altera o modelo para algo mais próximo do seguinte: produção-circulação-distribuição/consumo-reprodução. As conseqüências desse novo modelo seriam as três formas distintas pela qual a 
mensagem é recebida: dominante (decodificação da mensagem tal qual ela foi pensada, de acordo com um conteúdo hegemônico), negociada (mistura de elementos de adaptação e de oposição), e oposicional (fruir a mensagem de forma globalmente contrária, destotalizando-a).

Embora o próprio Stuart Hall tenha mais tarde considerado que a proposta deste modelo traz em si algumas falhas e contradições - como por exemplo o grande desafio que é pô-lo em prática sem que haja interferência das estruturas - ele ainda significa um passo adiante para estudar fenômenos sociais como a fanfiction. Ora, se os espectadores de um programa de televisão se contentassem em apenas receber esse conteúdo de forma uniforme, como seria possível que parte da audiência estivesse interessada em produzir um novo conteúdo baseado no que acabara de ver, em vez de simplesmente desligar o aparelho e seguir com suas vidas? O modelo proposto por Hall - que já tinha em mente o espectador de TV como sujeito pós-moderno - estava imbuído das conotações políticas dos Estudos Culturais, pois tornava a dar ao povo o que é do povo: a capacidade de produzir e interferir na cultura popular, ainda que esta estivesse sendo veiculada por outras esferas de poder.

Já é possível, neste ponto da nossa argumentação, categorizar a prática da fanfiction como um fenômeno pós-moderno. Podemos citar aqui algumas dos conceitoschave que a noção de pós-modernidade ganhou nas últimas décadas: versatilidade, esvaziamento das hierarquias, jogo do hegemônico contra subalterno, apagamento entre alta e baixa cultura, celebração da ambigüidade e fragmentação. Os meios de comunicação de massa criaram, de forma inconsciente, condições necessárias para que essas características sobressaltassem no cenário atual, e as subculturas parecem se adequar a essa colcha de retalhos.

As categorias enumeradas por Stam para conceituar o pós-modernismo - que por sua vez, cita diversos outros teóricos, como Jameson, Derrida e Lyotard - são: a retirada do referencial do real, no qual a história real é substituída por uma história imaginária; a rarefação do sujeito, onde o ego é transmutado para uma construção fraturada e discursiva; a desmaterialização da economia, onde a produção de objetos é trocada pela produção de signos e de informação; o colapso da distinção entre a alta e baixa cultura (conhecida definição de Andreas Huyssen); o sentido histórico atrofiado, onde haveria 
falta de “profundidade” e “desvanecimento do afeto” (2005: p. 217); e o dissenso em vez de consenso, pois as comunidades negociam suas diferenças a todo momento.

Não é preciso ir muito longe para chegar aos exemplos bem acabados de pósmodernidade na grande mídia. Os reality shows, por exemplo, promovem a celebração da identidade múltipla e da fuga da realidade. "O cotidiano midiatizado se constitui como uma forma extremamente paradoxal de se fugir do cotidiano (...) Sair do anonimato sendo as mesmas pessoas de sempre, continuando seus rituais de pessoas anônimas.” (DUPRAT e PRYSTHON: 2007, p. 6). Nesse sentido podemos apontar outros casos recentes como os programas de TV que exploram os dramas pessoais, o cinema mockumentary e as comunidades digitais que celebram constantemente a paródia, a piada interna, o sarcasmo, a subversão estética e o culto à cultura pop. As comunidades de fanfiction o fazem até certo ponto, mas essa postura é mais comum em casos como o site YouTube, especializado em arquivar produções em vídeo de todo o mundo, ou nas comunidades do site de relacionamentos Orkut, cujos participantes criam espaços virtuais destituídos de propósitos sérios.

Aqui podemos até mesmo dar continuidade a esse aspecto da discussão: seriam as novas tecnologias de comunicação - principalmente aquelas ligadas à internet - as maiores responsáveis pela construção de uma atual pós-modernidade? O que sabemos até o momento é que a internet, os celulares, palmtops, câmeras digitais, webcams e muitos outros apetrechos tecnológicos têm sido ferramentas importantes para a formação de novas redes sociais, onde surgem novos paradigmas e reciclam antigos. Um deles é a interatividade, que na lógica capitalista, nada mais é do que uma constante disputa pela atenção de seu público, dando a ele o poder de dar e receber atenção tanto do emissor (o canal de TV ou de rádio, um portal de internet, um jornal impresso) quanto de outros receptores (leitores, ouvintes, espectadores, internautas). Outro ponto é o dilúvio de informações, que embora seja ainda mais complexo na internet, é um fenômeno global. A Humanidade passou pelos estágios do conhecimento transmitido de forma oral, depois aprendeu a materializá-lo em livros e agora está digitalizando todo o conhecimento existente, e este conhecimento não apenas o torna mais amplamente transmissível, como mais facilmente manipulável, pois dados digitais são meros impulsos elétricos que se apresentam a nós como signos. Finalmente, temos o próprio conceito de comunidade virtual, onde há uma grande celebração das identidades, sejam 
elas múltiplas, fragmentadas, ou totalmente artificiais. Surgem então os avatares e apelidos (nicknames ou nicks), onde o indivíduo pode se mascarar para ou fingir ser algo que não é, ou assumir facetas de sua personalidade que estavam ocultas na superfície da realidade. As comunidades também conduzem um imenso processo de deslocamento espaço-temporal, pois o espaço físico e o período histórico, que nos dão uma certa sensação de pertencimento, são solapados no ciberespaço, onde o não-lugar se torna o lugar de todos, e o gerenciamento desse espaço depende apenas dos próprios internautas. Não é por acaso que as subculturas se encontram na internet. "Não existe uma subcultura online única e monolítica, mas antes um ecossistema de subculturas, umas frívolas e outras sérias” (RHEINGOLD apud COSTA: 2002, p. 54).

Há aqueles, como o pós-marxista Baudrillard, que tenham uma visão bastante pessimista desse panorama, afirmando que vivemos em uma sociedade tecnocrática que hiper-valoriza os signos de tal forma que nos obriga a viver no "deserto do real", um mundo hiper-real que manipula os signos apenas para esvaziar os sentidos e manter o status quo. Entretanto, apesar de concordarmos com a crítica em parte, pois de fato há no pós-modernismo a "desvantagem” - na falta de uma palavra melhor - de que este dificulta a compreensão na base do discurso, pois grande parte dos discursos veiculados é apenas aparência, e foram criados com essa finalidade. Mas discordamos que absolutamente todo o conhecimento e informação seja simulacro, porque mesmo no “deserto do real” sempre existirá pessoas dispostas a construir significados precisos que norteiem nossa perspectiva em meio ao caos informacional.

O avanço técnico é uma realidade e nada mais justo do que utilizá-lo de forma criativa e libertadora, como um meio para se produzir vanguarda. "Sem dúvida, a tecnologia tem um papel crucial, se não o papel crucial, na tentativa da vanguarda de superar a dicotomia arte/vida e tornar a arte produtiva para a transformação do cotidiano" (HUYSSEN: 1996, p. 29). A fanfiction pode perfeitamente servir de laboratório para novas vanguardas literárias, e de fato vem incorporando esse papel ao subverter antigos gêneros literários e criar novos, sendo uma ferramenta de liberdade estética e de estilo para que escritores amadores alcancem espontaneidade. Maria Lúcia Bandeira Vargas, uma das primeiras a estudar fanfiction no Brasil, percebeu essa sintonia dos fãs com as novas tecnologias de comunicação para as audiências - em sua 
maioria concentradas na internet atualmente - e o entendimento que estes têm do seu papel dentro e fora do cânone oficial.

Os fãs teriam sido os primeiros a adotar as novas tecnologias com o fim de expandir o universo interativo de suas comunidades, os chamados fandom, e, dessa forma, seu modo de proceder em relação aos produtos culturais difundidos nos meios de comunicação de massa constitui uma referência na relação entre as produções caseiras e a indústria do entretenimento. O objetivo dos membros das fandoms não é impedir a circulação dos produtos da indústria do entretenimento, mas afirmar sua preferência por determinados produtos, da mesma forma que o direito de utilizá-los como inspiração para a realização de suas intenções sociais, especulações intelectivas e, naturalmente, produções culturais, geralmente sem fins lucrativos. (VARGAS: 2005, p. 53)

No entanto, apesar do fim lúdico, a fanfiction se consolida como subcultura quando transgridem o estabelecido no texto-base, no cânone da ficção da cultura de massa. Como forma literária não-oficial, a fanfiction é um instrumento para que as fandoms realizem subgêneros que são violações nas normas que os criadores originais firmaram nos enredos. O subgênero de fanfiction slash/yaoi, por exemplo, transforma personagens heterossexuais em homossexuais; o shipping ou shipper cria relacionamentos amorosos entre personagens, mesmo que estes não sejam íntimos na história original; os pastiches ou paródias ridicularizam os personagens e os colocam em situações nonsense; e os crossovers põem na mesma história universos ficcionais totalmente distintos (como, por exemplo, a fantasia de Harry Potter e a ficção científica de Star Trek). Em comum, todos esses subgêneros de fanfiction não se importam se estão radicalmente diferentes do que foi exposto no original, pois são apenas um canal para seus autores exporem sua visão criativa do cânone ou sua defesa "do que poderia ser”, ao subverterem as pretensões comerciais e autorais deste cânone em nome da diversão ou satisfação pessoal.

O slash promove exclusivamente relacionamentos sexuais entre personagens do mesmo sexo; geralmente entre personagens masculinos. É um tipo de fanfiction escrito por mulheres na maioria das vezes. A expressão teria surgido da fandom de Star Trek, no fim dos anos 1970s, com o símbolo "/" definindo uma relação entre personagens de ST, especialmente James T. Kirk e Spock (ou seja, K/S). Relacionamentos lésbicos podem ser chamados de femslash ou femmeslash. Fãs de mangá e anime preferem as 
versões japonesas dos termos: yaoi ou shōnen-ai para casais gays masculinos; e yuri ou shôjo-ai para lésbicas. Het é o oposto de slash, classificando como uma história de sexo explícito com foco em relacionamentos heterossexuais.

A fanfiction do tipo shipping une casais que não estão envolvidos - nem aparentam se envolver - em um relacionamento amoroso no cânone. Os fãs podem divergir no que consideram "relacionamento” entre dois personagens. Casais que não oficializaram o romance no cânone (mesmo com beijos ou relações sexuais entre eles) podem ou não ser considerados alternativos. Fãs que torcem para a união entre determinados casais no cânone também são chamados de shippers. Já no crossover, personagens de uma história existem - ou são transportados para - no mundo de outra história preexistente, ou então personagens de dois ou mais cânones interagem na mesma trama. Embora o mais comum seja o ficwriter promover crossovers entre cânones com temáticas e/ou ambientes semelhantes, como a união de seriados de ficção científica, é possível que outros autores prefiram criar mesclas entre universos seguindo apenas critérios pessoais, ou mesmo de forma aleatória, como os citados Harry Potter e Star Trek.

\section{Considerações finais}

Embora a internet, a partir dos anos 90, tenha facilitado o contato entre os escritores de fanfiction de uma forma que nenhum outro meio conseguiu antes, o processo de sociabilização entre essas pessoas já havia sido iniciado anos antes, com o progressivo surgimento das media fandoms e prosseguiria de qualquer outra forma. E sem a internet, estas pessoas também estariam produzindo suas fanfictions isoladamente, apenas por hobby e satisfação pessoal; esses textos poderiam ser lidos apenas entre familiares e amigos dos escritores. No entanto, o fanfiction aos poucos vem se consolidando como um fenômeno muito maior do que seus protagonistas poderiam aspirar. Eles agora podem ser lidos por qualquer pessoa com acesso à internet; os escritores não pagam para “publicar”, os leitores não pagam para ler. Após a leitura, há a chance de ampliar a comunicação, por e-mail ou comentários no site, e conversarem 
sobre o que os fascina naquele universo. E assim uma nova rede de relacionamentos tem início, tendo a fanfiction como catalisadora.

Para este artigo, foi particularmente importante penetrar na lógica interna de um fenômeno pouco estudado e revelá-lo como um potencial objeto de comunicação - sem ignorar, obviamente, seu potencial para análises de variados enfoques, tais como educacional, cultural, social, literário e tecnológico, para citar alguns. Assim como na vindoura TV digital, é fundamental prestar atenção ao fenômeno e acompanhar o que o futuro lhe reserva. A relação com a TV digital, apenas para fins comparativos, serviu para deixar claro que a passividade das audiências, tão defendida por diversas correntes da teoria da comunicação, precisa ser repensada em função das novas tecnologias, que por sua vez inspiram novas atitudes em todos os agentes da comunicação de massa. Pro bem ou pro mal, a TV digital vai apontar caminhos que a fanfiction - e as demais produções das fandoms - já abriram, de certa forma.

Os tempos mudaram; a indústria cultural diagnosticada por Adorno e Horkheimer também. Diversos escritores de seriados de TV atuais cresceram absorvendo programas, e as novas gerações aperfeiçoam erros das anteriores, criando produtos que são capazes de reunir necessidades comerciais com ousadia autoral. Já os espectadores estão cada vez mais distantes do estereótipo da "caixa vazia”, mais conscientes do seu papel de gerar demanda e exigir oferta, e não abrem mão das ferramentas de interatividade que lhe dão poder de barganha na hegemonia do processo de comunicação. Com um teclado na mão e uma idéia na cabeça eles podem mudar o jogo, mesmo que precisem, para tal, “pedir emprestada” a inspiração ao outro lado.

\section{Referências bibliográficas}

COSTA, Rogério da. A cultura digital. São Paulo: Publifolha, 2002.

HALL, Stuart. Da diáspora. Identidades e mediações culturais. Belo Horizonte: UFMG, 2006.

DUPRAT, Nathália e PRYSTHON, Ângela: Universos claustrofobicamente luminosos: cultura pop, marginalidade e ambigüidade no contemporâneo. Interin, v. 3, p. 1-11, 2007.

HEBDIGE, D. From culture to hegemony; Subculture: the unnatural break. In: DURHAM, M. G.; KELLNER, D. Media and cultural studies. Oxford: Blackwell, 2006. 
PRYSTHON, Ângela. Estudos Culturais: uma (in)disciplina? Comunicação e Espaço Público, Ano VI, nº 1 e 2, 2003.

STAM, R. Teoria do cinema: a poética e a política do pós-modernismo. In: GUINSBERG, J.; BARBOSA, Ana Mae. (eds). O pós-modernismo. São Paulo: Perspectiva, 2005, p. 215-226.

VARGAS, M. L. B. O fenômeno fanfiction: novas leituras e escrituras em meio eletrônico. Passo Fundo: Universidade de Passo Fundo, 2005.

\section{Notas}

1 Jornalista e mestrando pela Universidade Federal de Pernambuco (UFPE). E-mail: mestradofanfiction@yahoo.com.br. O presente trabalho foi realizado com o apoio da Coordenação de Aperfeiçoamento de Pessoal de Nível Superior - CAPES - Brasil, sob orientação da $\operatorname{Prof}^{\mathrm{a}} \operatorname{Dr}^{\mathrm{a}}$ Ângela Prysthon.

${ }^{2} \mathrm{O}$ cientista da computação Vint Cerf, que criou os protocolos TCP/IP usados atualmente afirmou que os dias da televisão atual estão contados, além de previr que, em breve, a maioria verá a televisão pela internet. Essa revolução pode significar a morte dos canais tradicionais em favor de novos serviços interativos. Disponível em: $<$ http://www1.folha.uol.com.br/folha/informatica/ult124u323365.shtml $>$. Acessado em: 29 ago 2007

${ }^{3}$ YouTube. Disponível em: <http://www.youtube.com>. Acessado em: 29 ago 2007

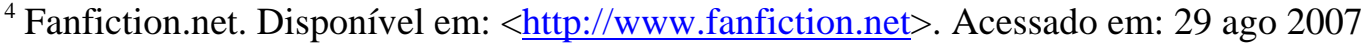

${ }^{5}$ Informações disponíveis em:

$<$ http://www.associatedcontent.com/article/312622/a_review_and_overview_of_fanfictionnet.ht ml>. Acessado em: 29 ago 2007

${ }^{6}$ Embora anime e mangá sejam respectivamente desenhos animados e quadrinhos produzidos no Japão, as categorias "quadrinhos" e "desenhos" normalmente comportam produções ocidentais, principalmente dos Estados Unidos. A distinção existe devido às grandes diferenças de perfil entre os públicos dessas categorias. Além do que, anime/mangá dividem a mesma categoria porque muitas histórias que surgem inicialmente em mangás também migram para produções em anime, ou vice-versa.

${ }^{7} \mathrm{Na}$ linguagem da fandom, o termo "cânone" refere-se às fontes "oficiais" na qual as fanfictions se baseiam, ou seja, os universos ficcionais originais. Existem diversos debates entre fãs para delimitar o que é ou não cânone, devido ao fato de que o processo de criação na indústria cultural ocorre de forma fragmentada, pelas mãos de diversos criadores em diferentes mídias e em circunstâncias distintas. Muitas vezes isso gera material com informações e características contraditórias. Enquanto alguns fãs adotam como canônico todo e qualquer produto lançado relacionado ao mesmo, outros radicalizam e só consideram como cânone as histórias escritas apenas pelo criador do conceito original. A acepção desta palavra segue uma definição própria do vocabulário dos fãs e difere do uso de cânone como "alta cultura" que é empregado pelos Estudos Culturais.

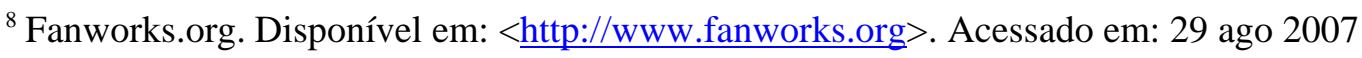


Revista da Associação Nacional dos

Programas de Pós-Graduação em Comunicação

${ }^{9}$ FicWad. Disponível em: <http://www.ficwad.com>. Acessado em: 29 ago 2007

${ }^{10}$ Fictionpress.com. Disponível em: <http://www.fictionpress.com>. Acessado em: 29 ago 2007

${ }^{11}$ SkyHawke. Disponível em: <http://archive.skyehawke.com>. Acessado em: 29 ago 2007

${ }^{12}$ AdultFanFiction.Net. Disponível em: <http://www.adultfanfiction.net>. Acessado em: 29 ago 2007

${ }^{13}$ FanDomination.Net. Disponível em: $<$ http://www.fandomination.net $>$. Acessado em: 29 ago 2007

${ }^{14}$ MediaMiner.Org. Disponível em: <http://www.mediaminer.org>. Acessado em: 29 ago 2007

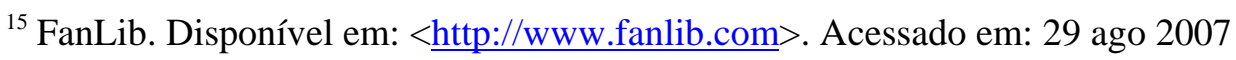

${ }^{16}$ TrekFanfiction.Net. Disponível em: <http://trekfanfiction.net>. Acessado em: 29 ago 2007

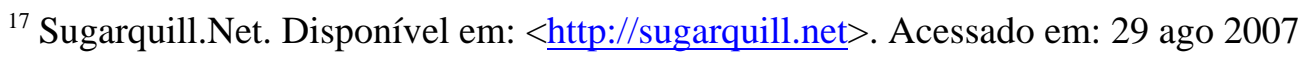

